\title{
LA REPÚBLICA INDEPENDENTE, EL PODER CONSTITUYENTE Y EL HÉROE DE LA EMANCIPACIÓN**
}

\author{
Patrice Vermeren ${ }^{* *}$ \\ Université de Paris 8 \\ vermeren.patrice@gmail.com
}

"Sabe Usted, señora, qué hay del general Bolívar?

Pues está muerto. ¿Sabe de qué?

De celos por el éxito de Rojo (Rojo y negro).

Stendhal, Carta a Albertina de Rubenpré

(Trieste, 6 de febrero de 1831)

"Estos tres hombres eran Napoleón, Bolívar y Beranger: Foy, Lafitte y Casimir Delavigne no tenían sino su estima. Fleury, ustedes lo adivinan, era del sur de Francia y debían terminar siendo responsables de algún periódico liberal"

Balzac, La mujer superior (1838).

"Erró acaso el padre angustiado en el instante supremo de los creadores políticos, cuando un deber les aconseja ceder a nuevo mando su creación, porque el título de usurpador no la desluzca o ponga en riesgo, y otro deber, tal vez en el misterio de su idea creadora superior, les mueve a arrostrar por ella hasta la deshonra de ser tenidos por usurpadores" José Martí, Simón Bolívar, 1893.

Resumen

¿Qué es un héroe de la emancipación? Rousseau comparaba el héroe antiguo, un guerrero triunfante que vence a los enemigos de su país, con el verdadero héroe, aquel que es capaz de posponer su singularidad en vistas a promover la acción común del pueblo soberano. De acuerdo con Miguel Abensour, la Revolución francesa redefine el heroísmo político como la capacidad de iniciar algo cuyo resultado es aún imprevisible, estableciendo así

Este trabajo ha sido redactado en el marco del Programa Franco-Argentino de filosofía ECOS-SCyT A98H03 (Instituto Gino Germani, Universidad de Buenos Aires y Centro de Investigaciones Políticas de la Sorbona, CNRS/ Universidad de París 1.

** Patrice Vermeren, docteur, professeur de philosophie et directeur du département philosophie de l'Université Paris 8, chercheur au Laboratoire d'Etudes et de Recherches sur les Logiques Contemporaines de la Philosophie, est membre fondateur du Collège International de Philosophie, délégué recherche à l'Institut des Amériques, membre du Conseil d'Administration du Polo Mercosur de Montevideo et professeur honoraire à l’Université du Chili et à l'Université Nationale de Cuyo. 
una nueva sociedad en la cual las figuras del héroe y del legislador coinciden, anudando una enigmática relación entre esclavitud y libertad, y estableciendo un orden que sobrepasa las divisiones generadas por los intereses injustos.

Pero si "el héroe es el verdadero sujeto de la modernidad" (Walter Benjamin citando a Baudelaire), ¿no es la posibilidad del heroísmo en la prosaica sociedad moderna y postrevolucionaria la llave de salida del siglo XIX? ¿Qué pensar de una figura heroica como la de Simón Bolívar, el usurpador del título de Libertador, según Benjamin Constant; el Napoleón de las retiradas, según Marx? ¿El partero de la emancipación, según escriben Pierre Leroux y Jean Reynaud en la Nueva Enciclopedia? ¿La luminaria de la emancipación del pueblo americano caído en la esclavitud, como dirá Juan Montalvo?

Palabras Clave: libertad, héroe antiguo y moderno, sujeto, modernidad.

\title{
Abstract
}

Who is a hero of emancipation? Rousseau contrasted the ancient hero, a triumphant worrier who defeats the enemies of his country, with the true hero, the one who is able to surrender his singularity in order better to promote the collective agency of a sovereign people. The French revolution, according to Miguel Abensour, redefines political heroism as the ability to initiate something in the unpredictability of the result, establishing therefore a new society in which the figures of the hero and the legislator coincide, broaching an enigmatic relationship between bondage and freedom, and establishing an order that supersedes the divisions generated by unjust desires. But if "the hero is the true subject of modernity" (Walter Benjamin quoting Baudelaire) is not the possibility of heroism in a prosaic modern post-revolutionary society the key issue of the nineteenth century? What to think of a heroic figure like Simon Bolivar, - the usurper of the title Libertador (Benjamin Constant)? The Napoleon of the retreats (Karl Marx)? The accoucheur of the emancipation, (Pierre Leroux and Jean Reynaud's New Encyclopedia)? The emancipating luminary of the American people fallen in bondage (Juan Montalvo)?

KEY WORDS: liberty, ancient and modern hero, subject, modernity.

\section{BOLÍVAR EL USURPADOR}

\author{
(Benjamín Constant y José Martí)
}

Dartiré de un artículo de Benjamín Constant publicado en El Correo Francés,
del 31 de diciembre de 1828, en la víspera de la sesión de la Cámara de Diputados
de 1829: ¿Qué quiere Francia? ¿Qué quiere y qué puede el siglo? Según Benjamín
Constant, garantías (el gobierno se las ha prometido, es necesario que las posean
plenamente), la igualdad (no solamente ante la ley, en los procedimientos y los usos:
la igualdad moral, es decir, el respeto de todo el desarrollo de la inteligencia y de todas
las profesiones útiles) y el mantenimiento del orden (contra el poder, como contra las
facciones, porque el poder perturba el orden cuando excede sus límites legales). ¿Bajo 
qué forma de gobierno Francia quiere garantías, igualdad, y el mantenimiento del orden? Bajo la forma del gobierno de la monarquía, tal como ésta ha sido fundada por la carta constitucional, que ha consagrado los principios de 1789; bajo la monarquía, con la abolición de privilegios y el fin de la arbitrariedad del poder ${ }^{1}$. Para expresar ese deseo de la nación, hay tres tipos de diarios: la prensa contrarrevolucionaria, rechazada por la opinión pública; los periódicos, que expresan la opinión de los ministerios y del gobierno, y los diarios constitucionales, los únicos que representan, para Constant, la opinión de Francia, y los únicos amigos de la libertad. Entonces Constant y sus amigos constitucionalistas declaran la guerra a aquellos que querían destruir o falsificar la carta constitucional, convertidos en sus enemigos. Ellos exigen, por otro lado, discutir libre y francamente con los amigos, que deben obedecer al doble imperativo, primero, de respeto inviolable a la libertad constitucional y segundo, de ser severamente justo, pero inexorable, frente a los ministros del gobierno si hacen mal y no hacen bien. La estrategia a la que es fiel Constant es la de hacer bloque a izquierda y centro izquierda contra los ministros de Martignac ${ }^{2}$.

La idea central de Benjamín Constant es que si se quiere la libertad para sí mismo, hay que respetarla en los otros. Y que combatir al enemigo con sus propias armas es diferir la libertad infinitamente. Es en este contexto que Constant evoca a Simón Bolívar, quien acaba de crear un consejo de Estado completamente sometido a él, y de proclamar la dictadura de la ilustración por decreto orgánico del 27 de agosto de 1828, que le confiere el poder ejecutivo y el legislativo, puesto que puede modificar, reformar o transgredir las leyes como quiera ${ }^{3}$. Constant dice que se equivocan al llamar a Bolívar el libertador de América meridional porque para asegurar el triunfo de sus partidarios, que eran minoritarios, no dudó en disolver la representación nacional de la Cámara de Diputados, con el pretexto de que al pueblo le faltaban luces para gobernarse. Bolívar confiscó todos los poderes y sancionó su dictadura con ejecuciones y asesinatos. Constant no ve ya en este hombre sino al usurpador. ¿Qué es un usurpador? Constant ya había dado esa definición en Del espíritu de conquista y de usurpación en 1815: "un usurpador es quien sin el apoyo del voto nacional toma el poder, o quien, revestido de un poder ilimitado, trastoca los límites que se le habían prescrito". "Nada puede legitimar un poder ilimitado", escribe Constant catorce años más tarde, "cuando un pueblo no está suficientemente ilustrado para ser libre, no es a la tiranía que deberá su libertad”. ¿En nombre de qué puede definirse el criterio de discriminación entre el pueblo ciego y estúpido y el pueblo ilustrado si la apreciación de las luces se confía a quienes les interesa la esclavitud de las naciones? Esta embestida debería, según Constant, hacer reflexionar a Simón Bolívar, que había sido antes sensible al juicio de algunos europeos, y en particular al suyo. Bolívar sirve aquí como figura emblemática de un dispositivo filosófico político que le sirve a Constant para desplegar un campo

Le Courrier français, diciembre de 1828.

Paul Thureau-Dangin 1876, p. 418 n. 1.

Hubert Gourdon 1984, n 29-30, p. 249 sq.

Benjamín Constant 1815, 1980, p. 253. 
polémico, agonístico, en el que él mismo encarna la defensa y la ilustración incondicional de las constituciones - sin condiciones de inaplicabilidad coyunturales. En realidad, Constant no cita a Bolívar al azar en el momento en que éste transforma en dictadura un poder que le había sido disputado, para unificar mejor a América del Sur. Constant hizo reunir un conjunto de artículos y libros sobre América Latina que contienen análisis informados sobre la política del libertador y son también reflejo de la recepción de esta política en Francia y en Europa ${ }^{5}$. La actualidad de Bolívar tiene que ver con el uso que acaba de hacer el abate Pradt: sin embargo, no es porque haya una divergencia sobre una cuestión ajena a los intereses de Francia, que se pone en peligro la unidad del combate de los constitucionalistas sobre lo que lleva al bien, todo lo que hace a las instituciones más sólidas y consolida las garantías, porque, dice Constant, para otras cosas, nosotros pensamos y juzgamos por nosotros mismos. Pradt responde para vengar a Bolívar de la acusación de usurpador, enfatizando las condiciones de emancipación de los pueblos latinoamericanos, donde todo es diversidad, división y ausencia de civilización: "para faltar a la libertad, hace falta que haya libertad", escribe Pradt. "La realidad es que en América las espadas que se habían dirigido contra el colonizador español para expulsarlo, se vuelven sin cesar unas contra otras. En conspiraciones fratricidas, facciones que no quieren sino leyes que sirvan a sus intereses particulares". La irresistible ascensión de Bolívar debe ser juzgada tomando en consideración esta coyuntura: la libertad es una idea nueva en América del Sur. Constant retoma la pluma y diseca la biografía de Bolívar, marcada por tantas manifestaciones de su deseo de abdicar, como por su obstinación en dar a los que lo rechazan, instituciones que él espera imponerles y plegarlos bajo el yugo de su poder usurpador ${ }^{6}$.

II

\section{EL HÉROE, VERDADERO SUJETO DE LA MODERNIDAD}

(Stendhal, Walter Benjamín y Miguel Abensour)

¿Qué es un libertador? O si se quiere, ¿Qué es un héroe de la emancipación? La cuestión del héroe en la modernidad procede de una genealogía que, si bien se invoca a menudo, invierte la concepción antigua del heroísmo. En Homero, el héroe Aquiles está animado por: 1) la crueldad; 2) la habilidad; 3) la injusticia. Mientras que, como lo ha mostrado Charles Zarka, las tres ideas reguladoras del héroe moderno son: 1) la idea de una justicia fundada en las reglas de la ética; 2) la idea de gloria, que es proporcional a los servicios rendidos a la humanidad; 3) el deseo de inmortalidad ${ }^{7}$. Zarka muestra cómo la ruptura de la concepción moderna del héroe frente a la concepción del héroe

John Potter Hamilton 1827; Basl Hall 1825; Gaspard-Théodore Mollien 1824.

Le Courrier français, 27 janvier 1829.

Yves-Charles Zarka 2001, p. 40. 
de la antigüedad se opera en tres momentos, cuyos nombres son: Maquiavelo, Baltasar Gracián y Vico. En Maquiavelo, el príncipe está construido como héroe político a partir de tres valores: la liberalidad, la generosidad, el valor. El problema central es el cuestionamiento del héroe como singularidad excepcional. De un lado, Maquiavelo pasa por el paradigma de los antiguos, como puede verse en el capítulo I del segundo discurso sobre la primera década de Tito Livio ${ }^{8}$. Contrariamente a Vico, en Maquiavelo hay una estructura ahistórica que postula una permanencia cosmo-antropológica que hace que los hombres no cambien de movimiento, de orden y de potencia. En consecuencia, la innovación política del príncipe no puede ser pensada como imitación de los antiguos que accedieron al poder por la virtud y no por la fortuna: Moisés, Cyrrus, Rómulo, Teseo. Pero también el príncipe como héroe político puede ser pensado retrospectivamente en la posible variación de la relación virtud-fortuna, como se muestra en el capítulo 25 de El Príncipe.

El segundo momento de la elaboración del concepto moderno de héroe sería la descripción hecha por Baltasar Gracián en El héroe ${ }^{9}$, capítulo I y II. Allí también hay una descripción del héroe por su singularidad, pero en el héroe de Gracián hay una dimensión estética que no estaba en Maquiavelo. El héroe no es solamente un entendimiento excepcional y un corazón magnánimo y valeroso, sino que posee, además del arte de hablar y de actuar, un estilo, una manera, una gracia. El heroísmo es el disimulado arte de aparecer. Finalmente, después de Maquiavelo y Gracián, viene Vico con De mente heroica ${ }^{10}$, quien le da al héroe toda su dimensión histórica. El héroe ya no es un ser singular o excepcional. El héroe es el miembro de una casta o de una clase que viene a caracterizar una época de la historia de las naciones, la edad de los héroes, que está situada entre la época de Dios y la época de los hombres. Las virtudes heroicas están ligadas al momento de formación de las sociedades aristocráticas. Los mejores se distinguen por la piedad frente a los dioses, la prudencia, la templanza, el valor, la magnanimidad, la lucha contra las bestias feroces, el cuidado en cultivar la tierra, la hospitalidad con los débiles y con los que están en peligro. La fuerza de los héroes se expresa en la dominación brutal de una casta o de una clase sobre la plebe. Pero esta fuerza de los héroes es también su debilidad: la desaparición del héroe se anuncia cuando los plebeyos comprenden que son los iguales de los nobles y que comienza la época de los hombres.

¿Cómo se pasa de esa figura del héroe a la del héroe revolucionario? Para comprenderlo, podemos referirnos a Rousseau, quien escribe en 1651 un discurso sobre la virtud de los héroes ${ }^{11}$. Responde a una cuestión que la Academia de Córcega formulaba así: ¿Cuál es la virtud más necesaria para los héroes, y a qué héroes esa virtud les ha hecho falta?

\footnotetext{
Maquiavelo 2000.

Baltasar Gracián 1986.

Vico 1988.

Jean-Jacques Rousseau 1651, 1959-1995.
} 
No me refiero aquí a Zarka, sino al comentario de Rousseau hecho por Blaise Bachofen en el libro La condición de la Libertad ${ }^{12}$. Si Rousseau no envió su tesis concluida a la Academia es porque la pregunta contenía implícitamente la idea de valor, del coraje en el combate, que no se demostraba sino el día de la batalla. Pero Rousseau quiere oponer al héroe guerrero, al aristócrata conquistador, el héroe verdadero, el que transmite a su pueblo las virtudes heroicas. Entonces, no se trata de nuevo de un héroe en singular, de un hombre de excepción que pueda hacerse cargo él solo del conjunto de procesos de la acción política. Al contrario, el verdadero héroe se disuelve en el patriotismo, es decir, en la glorificación militar o política de la totalidad de la nación. Lo que se rechaza es el riesgo del héroe singular, que consiste en desplazar al pueblo como actor de su destino político. "El mundo ha estado a menudo sobrecargado de héroes; pero las naciones no tendrán jamás un número suficiente de ciudadanos". Entonces, ¿Qué es un gran hombre? ¿Qué es un hombre de Estado? Es alguien que consigue hacer que el pueblo en su conjunto actúe colectiva y políticamente y que, por lo tanto, elimina su propia singularidad. El ejemplo paradigmático es Licurgo, el legislador de Esparta, quien se distinguió por haber entregado su corona al pueblo, a los ciudadanos, su legítimo dueño, que no lo estaba pidiendo, después de haberle dado una Constitución a la democracia espartana. En este sentido, el verdadero héroe es el sabio. Hegel se hace eco de esta afirmación cuando dice que la virtud de los antiguos tiene un contenido sólido en la sustancia del pueblo. Rousseau define este héroe como ciudadano y patriota.

La figura del héroe revolucionario ha sido trabajada magistralmente por Miguel Abensour en sus textos sobre Saint Just ${ }^{13}$. Allí cita a Tocqueville haciendo notar que con la Revolución francesa surgen pasiones nuevas: amor a la gloria, fe en la virtud, confianza en las potencias del hombre y en su perfeccionamiento. La Revolución francesa va a producir hasta una nueva religión que sustituye el egoísmo individual, el heroísmo y la abnegación, y produce la nueva raza de revolucionaros. Son los historiadores republicanos Michelet y Quinet quienes insisten en la centralidad del heroísmo en las revoluciones modernas, entendiendo que para ellos el pueblo es el héroe, pero no un héroe como los demás. Miguel Abensour muestra cómo hay que escoger entre, por un lado, la puesta en escena del miedo a la muerte en el corazón de la relación política, donde no hay lugar para el heroísmo. O, siguiendo a Maquiavelo, Montesquieu, Michelet, Quinet o Hannah Arendt, no disociar la política de la virtud del coraje, de la magnanimidad, de la virtu, es decir, de un conjunto de cualidades o principios que tienen como carácter decisivo trabajar para restaurar un mundo común. En este segundo caso, la política como búsqueda del buen vivir, y la realización del hombre como viviente político o como ser para la libertad, requieren el descubrimiento del heroísmo. 
Walter Benjamin escribe que el héroe es el verdadero sujeto de la modernidad ${ }^{14}$. Toda la cuestión reside en la inversión paradójica del héroe revolucionario. El héroe que encontraba una garantía en la revolución, ¿no se vuelve al final él mismo garantía de la revolución? Aquel que rompe con los modelos, ¿no termina por convertirse él mismo en la fuente de los modelos? El revolucionario, ¿no se convierte en el instaurador de un nuevo dogmatismo? Abensour retoma la pregunta de Claude Lefort: ¿Qué es el heroísmo político? ¿Qué es comenzar algo nuevo, cuyo resultado es finalmente imprevisible? Como dice Edgar Quinet, "el gran hombre es aquel que rompe las fatalidades aparentes y se vuelve él mismo una nueva fatalidad”. Aquí se plantea la cuestión de la tensión entre servidumbre y heroísmo, la relación enigmática entre servidumbre y libertad, lo que Miguel Abensour ha replanteado a partir de sus lecturas de La servidumbre voluntaria de La Boétie ${ }^{15}$.

En todo caso, habría cuatro criterios del heroísmo político, según Abensour: Primero, la facultad de comenzar algo nuevo, cuyo resultado es imprevisible. Segundo, la idea de institución de una nueva sociedad, en la que se confunden la figura del héroe y la figura del fundador o del legislador. Tercero, la relación enigmática de la servidumbre y de la libertad en el heroísmo. Cuarto, la finalidad del heroísmo, teniendo como fin un estado de orden y de unidad que permitirá luchar contra el efecto de divisiones producidas por los deseos injustos. En esta perspectiva quiero plantear la pregunta del personaje filosófico y político de Simón Bolívar como héroe de la emancipación, en cuanto esta figura está pensada sistemáticamente en el espejo de su sombra, de su mono (en el sentido de Zaratustra), la figura de Napoleón.

Quiero indicar dos cosas. Primero, sobre esta figura de Napoleón existe otro texto de Miguel Abensour, Rojo y negro a la sombra de $1793^{16}$ ¿Qué pone en escena la figura de Julián Sorel, héroe literario de Stendhal? La interpretación tradicional identifica a Julián Sorel con Bonaparte o con Napoleón, por un lado, con quien destruye el antiguo régimen en Europa y realiza la Revolución francesa; y por otro lado, con quien una vez se hizo emperador, liquida la revolución francesa al repetir la estupidez monárquica. Para Abensour, es necesario invertir esta interpretación que identifica a Julián Sorel con Napoleón, mostrando que Sorel es la repetición de la secuencia trágica de la revolución y que detrás de Bonaparte está Dantón o Saint Just. Rojo y negro no es una novela de ambición, como dice Hyppolite Taine, ni una novela de heroísmo, como dice Alain Bloom. No se trata de la muerte del heroísmo por el triunfo del individualismo moderno, sino al contrario, por el amor, la última residencia opuesta a una modernidad víctima del sin sentido. Para Miguel Abensour, el heroísmo es una dimensión constitutiva de la Revolución francesa, es un modo de ser, una manera de existir en el campo político, y el criterio del heroísmo después de la revolución es ser capaz de actuar en forma extrema, hasta el riesgo de la condena a muerte, como Julián Sorel. Entonces, lo que

$14 \quad$ Walter Benjamin 1982, p. 108.

15 Miguel Abensour et Marcel Gauchet 1976, re-edición 2000 y seminario 2006.

16 Miguel Abensour 2006. 
Abensour ve en Rojo y negro es la cuestión de Stendhal: ¿es todavía posible el heroísmo en la sociedad moderna? Y si ese es el caso, ¿por qué vía, por cual camino se puede ser heroico en una sociedad anti-heroica, en una sociedad prosaica?

Antes de plantear esta pregunta para mirar el caso de Bolívar, quisiera aproximarla al concepto moderno de emancipación, tal como aparece en Vico, según Georges Navet. Primero, la emancipación tiene su origen en el rechazo de un estado de hecho. Ella designa el movimiento por el cual se abren un espacio y un tiempo que son irreductibles al tiempo y al espacio natural. Segundo, la emancipación es efectuada por un sujeto colectivo que no preexiste, pero que se construye en el movimiento y que recíprocamente lo efectúa. Tercero, todo movimiento de emancipación busca modificar las relaciones fundamentales entre los humanos y las modifica solamente con su mera existencia. Cuarto, puede, sin ninguna duda, aventurarse a decir que el tiempo de la emancipación es el único propiamente humano ${ }^{17}$.

Resumiendo, primero, definición del heroísmo como verdadero sujeto de la modernidad, como posibilidad "post" revolucionaria, en una sociedad anti-heroica y prosaica, según Abensour. Segundo, definición de la emancipación como rechazo de un estado de hecho, constitutivo de un sujeto de la emancipación, que procede del gesto de la emancipación y que engendra una modificación radical de las relaciones humanas y abre un tiempo que es el único tiempo propiamente humano. Quisiera aplicar estas consideraciones de Abensour y de Navet a la figura de Simón Bolívar como héroe de la emancipación en su proximidad y su distancia con la figura de Napoleón: Napoleón y Bolívar, o las virtudes del Libertador ${ }^{18}$.

III

LA INDIGNACIÓN COMO POSTURA FILOSÓFICA Y EL HÉROE DE LA EMANCIPACIÓN DE LA RAZA HISPANOAMERICANA COMO PROTAGONISTA DE UNA ILÍADA SEMI-BÁRBARA ${ }^{19}$

(Juan Montalvo, Napoleón y Bolívar)

¿Qué es un héroe de la emancipación? Para explorar esta cuestión, partiré de la obra del escritor, filósofo y periodista ecuatoriano Juan Montalvo. Nacido en Ambato, en la Cordillera, el 13 de abril de 1832, morirá en París, el 17 de enero de 1889, en el cuarto piso de un edificio que ocupa el número 26 de la calle Cardinet. Al morir el dictador Gabriel García Moreno, dijo: "Mi pluma lo ha matado", frase que le valió la celebridad.

17 Georges Navet 2002a.

18 Traducción de María del Pilar Díaz Castañón, profesora de Filosofía de la Universidad de La Habana.

19 Juan Montalvo 1882, reedición 1912, tomo 2, p. 115. 
Arturo Andrés Roig ha analizado las influencias sansimonianas y la dimensión utópica en su trayectoria liberal, así como su pretendido socialismo ${ }^{20}$. Fernando Aínsa escribió: "es un filósofo que desciende a la esfera de lo cotidiano para construir una obra en torno a la antinomia tiranía-libertad" 21 .

No quisiera considerar a Montalvo solamente desde el punto de vista de su estilo literario -respecto al cual se ha subrayado con razón "las cualidades raras, los neologismos, los préstamos a lenguas extranjeras, el equilibrio de las imágenes, de las historias, de las anécdotas, de las dicciones y de las realidades, la erudición"22 - sino desde el punto de vista de su estilo filosófico. En su prólogo a las Catilinarias ${ }^{23}$, Miguel de Unamuno sostiene que la indignación es lo que salva a Montalvo de la retórica. Me gustaría examinar esta indignación en tanto postura filosófica.

Esta posición ya se expresa en el título mismo de la primera revista que publica a partir de 1856: El Cosmopolita. No quiere escribir para los partidos, sino para el público. Su ámbito es el continente americano, incluso Europa y el mundo entero: su idea rectora es convertirse en ciudadano de todas las naciones, es decir, del universo. Pero no se trata de hacer abstracción de la política, "puesto que ella es lo que debe ser, lo más importante para los ciudadanos", sino de hacer política en la filosofía. "En cuanto a mí, pienso que un acontecimiento importante confirmado por los siglos, una frase o un apotegma filosófico aporta más a la instrucción y al placer que el flujo insípido y dislocado de términos vacíos que colma los espíritus vulgares, sin que nadie extraiga de ello provecho, e incluso en perjuicio de los buenos"24. Y en este estilo de hacer política filosóficamente, dando al acontecimiento su dimensión histórica respecto a la historia del mundo y de la filosofía- la distinción entre el antes y el después se expresa en la serie ideal de la historia de las ideas- hay en primer lugar, sitio para la alegría, el júbilo o, como indica el título de sus obras, la risa ${ }^{25}$. Es ello justamente lo que motiva su interés por el personaje de Don Quijote, "sublime encarnación de la veracidad de la virtud en forma de caricatura" ${ }^{26}$, que pertenece a todas las épocas y a todos los pueblos.

Lo mismo ocurre con el tema de la república. Al describir el sistema republicano en Francia, Montalvo se refiere a un anciano -Jules Ferry- al que sus adversarios

26 Juan Montalvo 1895, reeditado en la edición de los Siete Tratados, París, Garnier, 1912,

tomo 2, op. cit, p. 115 y ss.

Arturo Andrés Roig 1955.

Fernando Aínsa 1999.

Juan Valera 1902, p. 35, citado por Plutarco Naranjo: “¿Quién es Juan Montalvo?” Oeuvres choisies de Juan Montalvo. op. cit., p. 9.

Miguel de Unamuno 1925.

Le Cosmopolite, citado por Gabriel Jude, "Les œuvres de Montalvo", Oeuvres choisies de Juan Montalvo, op. cit.

Como es sabido, Le rire de Bergson aparecerá en 1900 y será publicado en español en 1904. 
consideran "un pobre hombre", arguyendo que siendo un buen hombre siempre había sido reelegido ${ }^{27}$, hasta que ocurre lo improbable: es derribado por la presión de la multitud que grita "abajo el prevaricador", tras una campaña de prensa conducida por Clemenceau. Pues en la Francia republicana no hay tolerancia para las especulaciones o los deslices en favor de un familiar: según Montalvo, el pueblo francés es fiel al honor, y para él los abusos de confianza son más graves que los crímenes. A diferencia de la Francia republicana, América permite que el partido de los tolerantes crezca y prospere: clara alusión al general Veintemilla, célebre bajo el apodo de "El Mudo", quien una vez derrotado por las fuerzas democráticas, vació las cajas de la banca ecuatoriana antes de abandonar el país. Pero también un modo de relacionar el hecho con su sentido propiamente filosófico, es decir, con la cuestión de la moral en política bajo la forma republicana de gobierno.

En otro texto de Le Cosmopolite, Montalvo aborda la cuestión del poder legislativo en la república. Para hacerlo, comienza por la referencia que brindan los griegos: Solón dijo que dio a los atenienses no las mejores leyes, sino las mejores que podían recibir, añadiendo, como observa Plutarco, que el legislador adapta las leyes a las cosas, y no las cosas a las leyes.

De la cultura clásica pasa a la especulación metafísica: "la ley natural es el principio y origen de la ley civil: quien lo ignore ignorará la política, y colocado en el eminente ámbito de la legislatura, no estará en su sitio: la felicidad del pueblo consiste en la sabiduría de quienes lo gobiernan; la ciencia que los dirige no es tan fácil como parece" 28 . Una vez más, el enfoque es propiamente filosófico y a priori, iniciado a través de una referencia a la república de los antiguos. De este modo, establece principios que a partir de este momento permitirán juzgar el ejercicio del poder legislativo en América Latina.

¿Qué es la ley? Pregunta difícil, que Montalvo remite a la que Hierón, rey de Siracusa, hiciera a Simónides: ¿Qué es Dios? Sabiendo que Simónides solicitó un día, luego dos y después cuatro para finalmente no responder, Montalvo afirma que él haría lo mismo si le hicieran semejante pregunta. Opone el criterio de Rousseau -la ley como expresión de la voluntad general- al de Bentham -las relaciones eternas son absurdos eternos- y cita a Sócrates tal como lo transmite Jenófanes: "la ley es lo que de común acuerdo los ciudadanos han decidido prohibir o autorizar”.

“Cuando los legisladores sepan qué es la ley, sabrán qué es la república. La república es el gobierno de todos por todos. La república pura, donde la virtud reina; donde todos son ciudadanos y toman parte en los asuntos del Estado, libre, soberana, generosamente; donde el pueblo tiene el derecho de votar; donde los magistrados reciben la magistratura como un empleo que requiere consejos; donde la pobreza honorable no en las Oeuvres choisies de Juan Montalvo, op. cit, p. 177. 
atrae el conflicto; donde ni la inteligencia ni la pobreza hacen que os dejen de lado". No resulta sorprendente que Montalvo evoque aquí a Montesquieu: el principio del régimen republicano es la virtud. Por ello los republicanos deben ser virtuosos, siendo la virtud política el corolario de la virtud moral. Con ello se opone a Richelieu, "ese Hobbes con sotana que aconsejaba no utilizar a las gentes honestas, con mayor razón si pertenecían al tercer estado: todo el secreto de la tiranía está encerrado en esas sombrías palabras".

También Montalvo evoca a Montesquieu para argumentar la buena distribución de poderes que permite establecer una buena democracia.

Ya Tiberio, que reinara más de veinte años, lo había probado en la Roma antigua. Pero ocurre lo contrario en América del Sur. "La enfermedad de las repúblicas latinoamericanas no consiste en el hecho de que sus leyes sean malas, sino en que las buenas no son observadas, $\mathrm{y}$ también en el hecho de que el poder ejecutivo ejerce sobre ella poderes exorbitantes, y cuando carece de ello, se los arroga con mano de hierro. La violación de la ley es un primer paso hacia la tiranía, y no lo aceptaría más que si el primer magistrado pudiera hacer este juramento: juro que he salvado a la patria".

Pero, ¿qué significa salvar a la patria? Para muchos, la patria son las órdenes, el salario, las bayonetas, el "partido". Sabido es que los tiranos juran siempre que han salvado a la patria. ¿Qué patria podrían salvar los tiranos, si no la tienen? Montalvo extrae de aquí una reflexión sobre el despotismo en América Latina, donde el poder ejecutivo es siempre predominante, donde el legislativo es nulo o envilecido, y el judicial representa abandono y perversión. ¿Qué república es esa, en que el poder legislativo no es ni más ni menos que un apéndice del ejecutivo?, se pregunta Montalvo. "Necesitamos instruirnos para constituirnos convenientemente. Necesitamos civilizarnos para conocer nuestra verdadera felicidad: esa felicidad de buena estirpe que nace de las virtudes cívicas, de la libertad mesurada, del patriotismo puro, de la igualdad bien entendida".

Lo que, siguiendo a Unamuno, podría caracterizarse como una postura filosófica de la indignación, pasa por una referencia a la moral de quien se espera sustente la política, y por esa capacidad de juzgar el acontecimiento desde el prisma de una historia del mundo concebida como historia de las ideas. Se trata de una confrontación con lo universal, que se manifiesta en la apropiación de un saber que toma de la Grecia y Roma antiguas sus paradigmas, en el estilo de las lecturas francesas de Montalvo: Lamartine, Quinet, Michelet y Renán. De este modo accede, más allá del liberalismo político y su dimensión utópica, a la dignidad de una filosofía del exilio ${ }^{29}$.

Prueba de ello es la relación que Montalvo establece entre Napoleón y Bolívar en su tratado sobre Los héroes de la emancipación de la raza hispano-americana ${ }^{30}$, 
uno de los siete que publicara en Besançon en $1883^{31}$. En él compara a Napoleón con Bolívar, por considerarlos, sin duda alguna, como los hombres más destacados de la época en lo referente a la guerra y la política. Pero Montalvo considera que si su genio los asemeja, difieren radicalmente en cuanto a los objetivos que persiguen.

Por una parte, Napoleón, nacido de la tempestad, se apropia de su fuerza y estremece al mundo, que aún tiembla: "Dios convertido en hombre, fue omnipotente". Pero es el dios de los abismos, dedicado a implantar la servidumbre y no a eliminarla, que ensombrece la tierra con sus siniestros reflejos. Ser imperfecto en demasía, "mortal, demonio u ángel", provisto de un algo extra que lo coloca por encima de todos los seres superiores del género humano ${ }^{32}$, aun cuando se trate de seres dotados de un sentido, que actúan como una rueda en la máquina del entendimiento, una fibra en el corazón, creando un espacio en lo más profundo de ellos mismos. "Toma la revolución entre sus brazos y la ahoga a sus pies. Las naciones alzan la cabeza, miran al gigante con temor y doblan la rodilla. Fundió cien coronas en una sola". En este sentido, el encarnizamiento de Napoleón no aludiría solo a una forma de existencia política negativa, sino también a un terreno histórico, el de la revolución, que lo constituiría como la última figura del Antiguo Régimen y de la opresión de los pueblos.

Como Napoleón, Bolívar posee el fuego de la inteligencia y un corazón de recia estirpe. ¿En qué podrían diferenciarse? Uno se consagra a destruir las naciones y el otro a formarlas; uno a dominar a los pueblos y el otro a liberarlos. Serían dos polos de la esfera política, vecinos en el heroísmo. Y como los héroes, son astros ${ }^{33}$, Napoleón semeja a un cometa que infesta la bóveda celeste y aterra al Universo, mientras Bolívar sería un astro benefactor cuyo fuego destruye a los tiranos e insufla vida a los pueblos muertos, caídos en la esclavitud. Los dos nacieron de la revolución, pero el primero concluye el tiempo que le ha precedido al declararse opresor de los opresores y de los oprimidos; el segundo realiza los fines de la revolución: derribar a los tiranos y establecer los derechos del hombre en un vasto continente.

Estos dos héroes tan opuestos se asemejan también en la muerte, uno encadenado en medio de los mares, en la isla de Santa Elena, el otro proscrito y solitario a la orilla del mar, cerca de Santa Marta. Pero su posteridad los separa: la obra de Napoleón será destruida, mientras que la de Bolívar prospera. Entonces, ¿cómo es posible que el héroe de la emancipación sea menos conocido por los pueblos que el héroe de la opresión?

31 Fueron redactados en Ipioles, una aldea de Colombia, en 1870. Los otros seis tratados se titulan: De la nobleza, De la belleza en el género humano, Réplica a un sofista seudocatólico, Del genio, Los Banquetes de los Filósofos y El Buscapié (sobre Don Quijote). Entre los que menciona a Platón, por la inteligencia; a Newton, por el conocimiento de lo desconocido; a San Bruno, por la inocencia y a Carlos Borromeo, por la caridad.

33 Cf. Miguel Abensour y Valentín Pelosse, "Liberar al encerrado", y Jacques Rancière, prefacio en, Auguste Blanqui, La eternidad por los astros 2002. Ver también Horacio González, Retórica y locura 2002. 
Según Montalvo, es España la responsable, y también el hecho de que a Bolívar le faltara la pluma de un Chateaubriand, de una Mme. de Staël, de un Manzoni, de un Victor Hugo o de un Lamartine. Montalvo, que escribe sobre la importancia del periodismo en el mundo contemporáneo, tiene quizá conciencia de que es él quien ha de realizar la obra reparadora, y contribuir a hacer visible el destino de Simón Bolívar, para darle su justo lugar tanto en la memoria de los pueblos como en la historia.

\title{
IV
}

\section{EL LIBERTADOR COMO ALUMBRADOR DE LA EMANCIPACIÓN DE LA AMÉRICA DEL SUR Y LA CUESTIÓN DEL UNO EN LA CONSTITUCIÓN DE LA FAMILIA LATINOAMERICANA}

\section{(Pierre Leroux y Jean Reynaud)}

\begin{abstract}
Esta comparación entre Bolívar y Napoleón no es nueva. Sabido es que Bolívar llevaba en su biblioteca de campaña relatos sobre la vida y campañas de Napoleón. Por citar solo un ejemplo, valga recordar que en L'Encyclopédie Nouvelle, Jean Reynaud escribía en 1839 que a los ojos de la posteridad, la emancipación de la América meridional será quizá juzgada como el acontecimiento político más considerable del siglo XIX, por ser un gran cambio en la condición general del ser humano, pues si los combates de Napoleón y sus secuelas tienen su origen en el siglo XVIII y la Revolución francesa, de la que no son más que un apéndice, la revolución en América es propia y particular del nuevo siglo.
\end{abstract}

Reflexionando sobre tal asunto desde la metáfora del nacimiento, los pueblos no han asignado a Bolívar la paternidad, sino la ayuda en el parto, y de importancia vital: "ha forzado a nacer a ese feto de la naturaleza". Se trata de una ayuda a los pueblos subyugados de América del Sur en su obra de autoemancipación que comienza por la revuelta de algunos criollos civilizados y llaneros (mestizos del campo) contra la madrastra España, que quiere retener a sus colonias en la impotencia y la imbecilidad, con un clero sometido a la monarquía. Paradoja mayor, la reivindicación de la independencia estalla como reacción a la abdicación de los borbones españoles y su sustitución por José Bonaparte, por lo que la revolución republicana pasa primero por una reivindicación realista, con la rebelión conducida por el general Miranda, antiguo compañero de Washington. Bolívar tiene todo el derecho a ser llamado "Libertador", por haber ayudado con su genio guerrero a los pueblos en su obra emancipadora, aun cuando se detenga en el umbral de la obra legisladora.

Proveniente de una de las familias más ricas y nobles de la colonia, Bolívar hizo sus estudios en España y visitó Europa. Durante su estancia en Francia asiste -escena premonitoria- a la proclamación del Emperador en Saint-Cloud, el 18 de mayo de 1804, y luego a la coronación de Napoleón por el Papa el 2 de diciembre de 1804. Reynaud califica este acontecimiento de "acto potente de lo político, que transformaba, cierto es, a un general liberador en un amo, pero que también, es preciso admitirlo, era un claro testimonio del valor y el triunfo de la unidad”. Bolívar también asiste al matrimonio con María Luisa de Austria en Notre Dame de París. 
Para esbozar la figura de Napoleón, Reynaud se inspira sin duda alguna en un curioso artículo de Pierre Leroux que apareciera en 1829 en Le Globe ${ }^{34}$ y que iba en contra de las opiniones liberales profesadas por el periódico. Se describe a Napoleón como quien quiso generalizar en Europa los resultados de la Revolución francesa, y extender la civilización francesa significaba preservarla: "Preservar a Francia cambiando a Europa, he ahí el problema que se ofrecía a Napoleón", escribe Leroux. "Para resolverlo, no llamó en su ayuda a la insurrección ni a los oradores o los clubes; no creó ruinas que hubieran estorbado su paso; quiso hacerlo todo con ejércitos, administradores y su Código. En otros términos, proceder así significaba fundar un gran imperio unitario, una monarquía europea" ${ }^{35}$.

Como Leroux, Reynaud hace de la unidad el principio de la acción política de Napoleón. Pero también de Bolívar: justamente por no estar convencido del resultado de las tentativas de federación, el caraqueño se uniría tardíamente al campo de la revolución. Al huir de la fortaleza española de Puerto Cabello y llegar a Cartagena, despliega el proyecto emancipador: reunir a toda América por la fuerza y de un solo golpe. Reynaud se pregunta si su plan -encerrar al enemigo en un nudo gigantesco entre Nueva Granada (Colombia), Venezuela y Quito- vendría de Dios o de los hombres, pero se ve obligado a constatar que el Libertador obra como era necesario hacerlo desde el primer momento. El objetivo de la emancipación justifica los medios; Bolívar lanza en el mismo lugar su famosa declaración de guerra a muerte contra los españoles: "Todo español que no conspire contra la tiranía en pro de la buena causa, por todos los medios más activos y eficaces, será considerado enemigo, castigado como traidor a la patria y por consiguiente irremediablemente pasado por las armas". Y se hace nombrar dictador, concentrando toda la fuerza de un gobierno militar y absoluto en Caracas. Luego dimite, reinicia los combates, huye a Jamaica y regresa para reconquistar Venezuela, esta vez no por Colombia, sino pasando por la Guyana.

En este trayecto, lo que se forja es algo más que una de las figuras posibles de su destino: la realización del principio bajo cuya condición el hecho de la emancipación y el advenimiento de la independencia de América Latina se harían posibles. Según Jean Reynaud, Bolívar pisotea la Constitución federal, hace declarar la unión en un solo Estado de todas las provincias de Venezuela y Nueva Granada, resumen de su vida política y su más alto título a la inmortalidad. La liberación de Colombia no podía sostenerse sin la de Perú y Bolivia: el Libertador, tras haber creado naciones, piensa en una familia de naciones, de México a Buenos Aires. El Congreso de Panamá llama a una Santa Alianza republicana en contra de la Santa Alianza monárquica. Pero Ecuador y Perú se rebelan y acusan a Bolívar de tiranía. En un gesto digno de los antiguos,

34 Pierre Leroux, "Philosophie de l'histoire. De la politique extérieure au dix-neuvième siècle, et du perfectionnement du droit international ( $1^{\text {er }}$ article. Système de Napoléon"). Le Globe, 24 de junio de 1879, retomado en Pierre Leroux, Aux philosophes, aux artistes, aux politiques. Trois discours et autres textes, établi et préfacé par Jean-Pierre Lacassagne, postfacio de Miguel Abensour, pp. 41 y ss.

35 Pierre Leroux, op. cit., p. 46. 
escribe Reynaud, el Libertador renuncia al poder presidencial y toma el camino del exilio. Nunca llegará a Europa: muere de fiebre, a los 42 años, cerca de Santa Marta. Había dicho: “¿Me creen tan insensato como para degradarme a mí mismo? ¿No es el título de Libertador más glorioso que el de soberano?”

La imagen de Napoleón aparece aún dos veces más en este texto. En primer lugar, para indicar que Bolívar se opone radicalmente a un posible establecimiento del Emperador en Luisiana, si lograba huir de Santa Elena ${ }^{36}$. Pero en la evaluación que Reynaud hace de la vida de Bolívar, afirma que este último era de la escuela de Napoleón, y que había sabido aprovechar las lecciones de su caída al igual que sus victorias, como lo atestigua el decreto de muerte a los españoles, la reunión en un solo cuerpo nacional de Venezuela, Quito y la gran Colombia, y la incitación a las naciones americanas a estrechar sus lazos y unirse en una sola familia. De este modo, Reynaud construye una posteridad gloriosa al Libertador, en el mismo sentido en que Pierre Leroux quería continuar los planes de la Revolución y de Napoleón: “comprender el pensamiento que presidía a la conquista y seguir este pensamiento por otras vías”.

Domingo Faustino Sarmiento, en Facundo, aparecido en 1845, cita este artículo de Jean Reynaud para presentar el arquetipo de la incomprensión que habría sufrido Bolívar por parte de todos sus biógrafos de Europa y de América. Estos lo habían

Cf. la carta escrita en Kingsley por Simón Bolívar al Presidente de las Provincias Unidas de Nueva Granada, citada por Germán Arciniegas ("Napoleón o Washington", en Cahiers de l'Herne, 1986, p. 213): "Han llegado cartas oficiales de Inglaterra: se anuncia la ocupación de París (...) por los ejércitos aliados contra Francia; la restauración del rey Luis XVIII y la evasión de Napoleón Bonaparte. El futuro del mundo se decidió en Waterloo. Esta batalla inmortal que liberó a Europa puede tener consecuencias más importantes que todos los conflictos que están grabados en los anales de la humanidad, sobre todo para América: se corre el riesgo de ver renacer en su seno el teatro de la siniestra y terrible guerra que afligiera a Europa durante más de 20 años. Si es cierto, como se asegura, que Bonaparte ha huido de Francia y viene a buscar asilo en América, destruirá sin dudas el país donde se establezca. Atraerá el odio de los ingleses por la tiranía, y la cólera de Europa; los ejércitos de todas las naciones le seguirán, y eventualmente toda América podría sufrir el bloqueo de las escuadras inglesas (...) Si Napoleón halla asilo en América del Norte, eso terminará en una guerra con Europa; Napoleón intentará entonces aliarse con sus vecinos mejicanos, partidarios de la independencia. Si es la América del Sur la víctima de este golpe-la llegada de Bonaparte- y lo acogemos amigablemente, pobres de nosotros, esa será nuestra condena eterna. Su sed de conquistas es insaciable; para satisfacer sus ambiciones, ha matado a la flor de la juventud europea en los campos de batalla; llegará al Nuevo Mundo con los mismos designios, donde espera de seguro sacar provecho de nuestras discordias para apropiarse de ese gran imperio, incluso al precio de la poca sangre que quede en nuestras venas, como si América no fuera lo bastante desgraciada ni estuviera suficientemente devastada por la guerra con España, que nos ha exterminado (...) Vuestra Excelencia, si este último golpe se asesta a nuestro país, insisto en que nuestra elección sea clara, sea cual sea nuestra política: debemos combatir a Napoleón, porque es el precursor de calamidades peores que las que sufrimos $(\ldots) "$. 
asimilado a cualquier general europeo dotado de cualidades superiores, sin ver lo que él era realmente: un caudillo popular, es decir, no solamente un caudillo, sino la manifestación de la vida interior de un pueblo tal como la han obrado la colonización y las particularidades del terreno, y que permite por lo mismo comprender su ideal y su personificación: "Sin estos antecedentes, nadie comprenderá a Facundo Quiroga, como nadie, a mi juicio, ha comprendido todavía al inmortal Bolívar, por la incompetencia de los biógrafos que han trazado el cuadro de su vida. En la Enciclopedia Nueva, he leído un brillante trabajo sobre el general Bolívar, en que se hace a aquel caudillo americano toda la justicia que merece por sus talentos, por su genio; pero en esta biografía, como en todas las otras que de él se han escrito, he visto al general europeo, los mariscales del imperio, un Napoleón menos colosal; pero no he visto al caudillo americano, al jefe de un levantamiento de las masas; veo el remedo de Europa i nada que me revele a América" ${ }^{37}$. Para comprender el drama del personaje de Bolívar es necesario ponerlo en la escena con los decorados y las vestimentas americanas, porque el personaje histórico, con su atuendo, sus ideas, su método de acción, no aparece en su verdad histórica si no está implantado antes en el terreno, el paisaje, el teatro en el cual la pieza se va a jugar.

\section{V}

EL 18 BRUMARIO DE SIMÓN BOLÍVAR, O EL NAPOLEÓN DE LAS RETIRADAS

(Karl Marx, Bolívar y Napoleón III)

Pero el Libertador puede también aparecer como un antihéroe. En un artículo publicado en The New American Cyclopaedia (1853-1863) ${ }^{38}$ bajo el título de "Bolívar y Ponte", Karl Marx lo describe como un cobarde. Así, sostiene que Bolívar rehúsa unirse a la revolución de 1810 en Caracas, negocia sin empacho armas en Londres, huye y abandona a sus hombres en la masacre tras la revuelta de los prisioneros en Puerto Cabello, entrega al general Miranda a los españoles, triunfa sin gloria sobre un ejército español compuesto por indígenas que huyen en cada batalla y que está dirigido también por cobardes:

"Como la mayoría de sus compatriotas, era enemigo de todo esfuerzo prolongado, y su dictadura cayó pronto en la anarquía militar; los asuntos más importantes estaban en manos de favoritos que dilapidaban las finanzas del país y recurrían luego a medios odiosos para restaurarlas".

Del mismo modo, sostiene que tras cada combate, Bolívar huye abandonando sus tropas, y son los otros generales quienes ganan las batallas; también saquea las ciudades que se

37 Domingo Faustino Sarmiento 1961 p. 18; Susana Villavicencio 2008.

38 Karl Marx 1858-1863, reeditado en francés por Louis Janover, Arles, Sulliver, 1999. 
habían rendido. Añade que más tarde, será juzgado como “desertor y haragán”, por Brion. Va en busca de refuerzos y no regresa, provocando una masacre; Piar, el conquistador de la Guyana, lo apoda “el Napoleón de las retiradas", y Bolívar se venga haciéndolo fusilar. Establece tratados prematuros con los españoles y amenaza constantemente con renunciar. Llega a sostener las ambiciones de los federalistas, con el fin de legitimar y mantener su dictadura. Su propia renuncia es forzosa, habiendo intentado hasta el último momento conservar el poder.

Por otra parte, relata que el general Ducourchey Holstein informa que Bolívar solo disfrutaba de sentarse y extenderse perezosamente en su hamaca, permitiéndose accesos de furia que eran casi crisis de locura; es apasionado por las lecturas francesas fáciles, el vals y montar a caballo, y le encanta oírse hablar y hacer brindis.

Ya no se trata de Napoleón Bonaparte, sino de Napoleón III, como Marx indica en una carta a Engels: "Respecto a lo del estilo tendencioso (de mi artículo sobre Bolívar) admito haberme alejado un poco del tono de la Enciclopedia. Da demasiada rabia ver comparar al cretino más cobarde, más vulgar y más miserable, con Napoleón I. Bolívar es un verdadero imbécil"39.

En "Le Libertador tel qu'en lui même?" ${ }^{40}$, Louis Janover muestra que es Bolívar quien moderniza profundamente la sociedad sin cambiar sus bases, y que tras la imagen de un lector de Voltaire, de Montesquieu o de Rousseau, Marx ve en Bolívar las huellas del bonapartismo clásico, al igual que del tribuno popular y manipulador, cuyo análisis hiciera en El 18 Brumario de Luis Bonaparte. Habría que añadir que en esta época Bolívar no disfrutaba de una buena imagen en la prensa: los liberales le reprochan tanto el centralismo como su autoritarismo, mientras que los republicanos desconfían de él, considerándolo como un monarca en potencia; su reivindicación de la unidad latinoamericana es tomada por una actitud anti-europea ${ }^{41}$.

En América Latina, "Bolívar y Ponte" fue publicado en 1936 con un prefacio de Aníbal Ponte, que declara su completo acuerdo con Marx, debido a que quiere combatir las teorías nacionalistas latinoamericanistas de Víctor Raúl Haya de la Torre y José Vasconcelos ${ }^{42}$, y rechaza todo valor a un bolivarianismo democrático y antiimperialista que se haga en nombre de una exaltación heroica de Bolívar, tesis por otra parte de amplio futuro ${ }^{43}$.

40

41

Correspondencia Marx y Engels, carta de Marx a Engels del 14 de febrero de 1858, op. cit., p. 30.

Louis Janover, op. cit. pp. 28-43; cf. también Maximiliano Rubel 1960.

Pedro Scaron 1979, pp. 28-43; cf. también José Aricó 1980, Catálogos, pp. 116 y ss., y nota VII, p. 178 y ss.

Aníbal Ponce 1936, retomado en Aníbal Ponce, op. cit.

Cf. por ejemplo Ricardo A. Martínez 1957, p. 97: "Las ideas internacionales de los libertadores fueron en su época simples anhelos utópicos; pero en la época en que vivimos, son consignas de lucha anti-imperialistas", citado por Germán Carrera Lamas, El Culto a Bolivar 1973; ver también Louis Janover, op. cit., p. 39. 
Habría que preguntarse: ¿existe un futuro para la figura del Libertador como héroe de la emancipación? Para delimitar los contornos conceptuales, habría que recurrir a los análisis realizados por Miguel Abensour, que establecen cómo el creciente olvido de la política conduce necesariamente a redescubrir el heroísmo ${ }^{44}$. También se impone la remisión a los trabajos de Georges Navet ${ }^{45}$, quien, comentando De la Mente heroica de Vico -traducido por Michelet-, destaca la fuerza activa y autónoma destinada a dejar su huella-favorable o no-sobre el acontecimiento revolucionario.

Sería cuestionable entonces la ideologización o la mitologización del héroe de la emancipación no como una figura posible del olvido político, sino desde una posición singular en la relación enigmática entre la servidumbre y la libertad. Dicho de otro modo, el Libertador, al ofrecerse como modelo de modelos, como causa sui para sí (Stanislas Breton) no logra desanimar la imitación. De ahí que el fracaso personal de Bolívar sería la condición de posibilidad de la invención de la república en América Latina, y lo que le permitiría en el futuro erigirse en figura positiva de la emancipación, convertido a la vez en el doble y la negación de Napoleón. Como ha mostrado Ana Cecilia Ojeda ${ }^{46}$, ese "Dios terrenal", según la expresión de Pablo Neruda" ${ }^{47}$, que fuera celebrado por Gabriel Picón Febres en estos términos:

César o Napoleón por la estatura

Los ojos negros, el perfil romano

$\mathrm{Y}$ en la perfecta urdimbre de la mano

El nervio de la ibérica bravura ${ }^{48}$.

Podrá también ser comparado por Rubén Darío ${ }^{49}$ al cóndor andino, admirado por su majestad y potencia, y su vuelo sobre los Andes deviene símbolo de la libertad, del Chimborazo al Torquemada

\section{Referencias bibliográficas}

Abensour, Miguel (1989), “Les paradoxes de l'héroïsme révolutionnaire”, Esprit, febrero, pp. 60-81.

(1995), "Rire des lois, des magistrats et des dieux", Jean Borreil. La raison de l'autre; prefacio de Maurice Matieu y Patrice Vermeren. Paris: L'Harmattan, pp. 85 y ss.

\footnotetext{
$44 \quad$ Miguel Abensour 1995, pp. 85 y ss.

45 Georges Navet 2002b.

$46 \quad$ Ana Cecilia Ojeda 1966; 2002.

47 Pablo Neruda 1941, citado por Ana Cecilia Ojeda, ibíd.

48 Gabriel Picón Febres, citado por Ana Cecilia Ojeda, ibíd.

49 Rubén Darío, citado por Ana Cecilia Ojeda, ibíd.
} 
(2006), "Rojo y negro a la sombra de 1793", Autour de Miguel Abensour, UNESCO, y Critique de la politique. Autour de Miguel Abensour, Sens et Tonka.

Abensour, Miguel et Marcel Gauchet (1976), Les leçons de la servitude et leur destin", La Boètie: Discours sur la servitude volontaire. Paris: Payot, reedición 2000; y seminario "Del buen uso de la hipótesis de la servidumbre voluntaria", Centro Franco-Argentino de Altos Estudios de la Universidad de Buenos Aires, 2006.

Aínsa, Fernando (1999), Presentación de las Oeuvres Choisies de Juan Montalvo. París, L'Harmattan. Colección "La filosofía en común”, publicadas con el colaboración de Mauricio Montalvo.

Aricó, José (1980), Marx y América Latina, cap. 8: "El Bolívar de Marx". Lima: Centro de Estudios para el desarrollo y la participación, $3^{\mathrm{a}}$. Edición, Buenos Aires, Catálogos, pp. 116 y ss., y nota VII, p. 178 y ss.

Bachofen, Blaise (2002), La condition de la liberté. Paris: Payot.

Benjamin, Walter (1982), "Le Paris du Second Empire chez Baudelaire", Charles Baudelaire, un poète lyrique à l'apogée du capitalisme. Paris: Payot, p. 108.

Carrera Lamas, Germán (1973), El Culto a Bolívar. Caracas: Universidad Central de Venezuela.

Constant, Benjamín (1815), De l'esprit de conquête et de l'usurpation dans ses rapports avec la civilisation européenne. Paris: Pluriel (1980) (ch. II, ajouté à la $4^{\circ}$ édition), p. 253.

Darío, Rubén, Oda (en ocasión del centenario de Simón Bolívar), citado por Ana Cecilia Ojeda.

González, Horacio (2002), Retórica y locura. Buenos Aires: Colihue.

Gourdon, Hubert (1984), "Les trois constitutionnalismes de Simon Bolivar", Cahiers des Amériques Latines 29-30: 249 sq.

Gracián, Baltasar (1986), El Héroe (1637). Barcelona: Arturo del Hoyo.

Hall, Basl (1825), Voyage au Chili, au Pérou et au Mexique pendant les années 1820 , 1821 et 1822. Paris: A. Bertrand.

Hamilton, John Potter (1827), Travels through the interior provinces of Colombia. Londres: J. Murray.

Janover, Louis, Le Libertador tel qu'en lui-même. Bolívar y Ponte. The New American Cyclopedia.

Le Courrier français, 27 janvier 1829.

Leroux, Pierre (1879), "Philosophie de l'histoire. De la politique extérieure au dixneuvième siècle, et du perfectionnement du droit international $\left(1^{\mathrm{er}}\right.$ article. Système de Napoléon", Le Globe, 24 de junio, retomado en Pierre Leroux, Aux philosophes, aux artistes, aux politiques. Trois discours et autres textes, prefacio de Jean-Pierre Lacassagne, postfacio de Miguel Abensour. París: Payot, Colección "Crítica de la política", pp. 41 y ss. 
Maquiavelo (2000), Discursos sobre la primera década de Tito Livio (1531). Segundo discurso. Buenos Aires: Alianza.

Martínez, Ricardo A. (1957), El Panamericanismo, doctrina y práctica imperialista. Buenos Aires: Editorial Alumine, p. 97.

Marx, Karl (1858), "Bolívar y Ponte", The New American Cyclopaedia. New York, 1858-1863, tomo 3, artículo fechado el 8 de enero, reeditado en francés por Louis Janover, Arles, Sulliver, 1999.

Mollien, Gaspard-Théodore (1824), Voyage dans la République de Colombia en 1823. Paris: A. Bertrand.

Montalvo, Juan (1882), "Los héroes de la emancipación de la raza hispano-americana. Simón Bolívar”, Siete Tratados. Imp. J. Jacquin, Besançon; reedición París: Garnier, 1912, tomo 2, p. 115.

(1995), "Rire des lois, des magistrats et des dieux", Jean Borreil. La raison de l'autre; prefacio de Maurice Matieu y Patrice Vermeren. Paris: L'Harmattan, pp. 85 y ss. (1895), El Buscapié. Prólogo de un libro inédito titulado Ensayo de imitación de un libro inimitable o capitulos que se le olvidaron a Cervantes. Besançon, Imp. J. Jacquin; reeditado en la edición de los Siete Tratados, París: Garnier, 1912, tomo 2, op. cit, p. 115 y ss.

(1995), "Rire des lois, des magistrats et des dieux", Jean Borreil. La raison de l'autre; prefacio de Maurice Matieu y Patrice Vermeren. Paris: L'Harmattan, pp. 85 y ss. "La République en France", publicado primero en $L e$ Spectateur y luego en las Oeuvres choisies de Juan Montalvo, op. cit, p. 177.

(1995), "Rire des lois, des magistrats et des dieux", Jean Borreil. La raison de l'autre; prefacio de Maurice Matieu y Patrice Vermeren. Paris: L'Harmattan, pp. 85 y ss. "De la République. Le pouvoir législatif", Le Cosmopolite, op. cit., p. 183.

Navet, Georges (2002a) L'émancipation, prefacio. Paris: L'Harmattan.

(2002b), "Rhétorique, imagination et mondo civile chez G. B.Vico", Les papiers du Collège International de Philosophie. París, n. 55, mars. Prefacio, en Joseph Ferrari, Machiavel juge des révolutions de notre temps. Paris: Payot; L'émancipation (Georges Navet, comp.). Paris: L'Harmattan.

Neruda, Pablo (1941), Canto para Bolívar, leído en la Universidad de México el 24 de julio, citado por Ana Cecilia Ojeda.

Ojeda, Ana Cecilia (1966), Le mythe bolivarien dans la littérature latinoaméricaine. Tesis de doctorado, Université de París III.

(2002) El mito bolivariano en la literatura latinoamericana. Aproximaciones. Bucaramanga: Ediciones Universidad Industrial de Santander.

Picaudé, Valérie y Patrice Vermeren (comp.) (1993), Filosofías del exilio. Valparaíso: Edeval.

Picón Febres, Gabriel, Sonetos a Bolivar, citado por Ana Cecilia Ojeda.

Ponce, Aníbal (1936), Prefacio a "Bolívar y Ponte", Dialéctica, 1 de marzo, retomado en, Aníbal Ponce, Obras Completas. Buenos Aires: Cartago, tomo IV, p. 562. 
Rancière, Jacques (2002), Prefacio en Auguste Blanqui, La eternidad por los astros. Buenos Aires: Colihue.

Roig, Arturo Andrés (1955), El pensamiento social de Juan Montalvo. Quito, Universidad Andina Simón Bolívar, Subsede Ecuador: Corporación Editora Nacional.

Rousseau, Jean-Jacques (1959-1995), Discours sur la vertu des héros (1651), Euvres Complètes, tomo 2. Paris: Gallimard.

Rubel, Maximiliano (1960), Karl Marx devant le bonapartisme. Paris: Mouton.

Sarmiento, Domingo Faustino (2008), Facundo. Edición Alberto Palcos. Buenos Aires: Ediciones Culturales Argentinas, 1961 p. 18.

Scaron, Pedro (1979), presentación de "Bolívar y Ponte", Materiales para la historia de América Latina. Cuadernos de Pasado y Presente, n. 30, México, pp. 28-43.

Thureau-Dangin, Paul (1876), Le parti libéral sous la Restauration. Paris: Plon, p. 418 n. 1.

Unamuno, Miguel de (1925), Prólogo a Juan Montalvo, Las Catilinarias, París: ed. Garnier frères.

Valera, Juan (1902), Carta-prefacio a la Geometría Moral de Juan Montalvo. Madrid: ed. Est.Tip. Sucesores de Rivadeneira, p. 35, citado por Plutarco Naranjo: “¿Quién es Juan Montalvo?” Oeuvres choisies de Juan Montalvo., op. cit, p. 9.

Vico (1988), De mente heroica (1732), presentación de Georges Navet, Cahiers du Collège International de Philosophie, Osiris, n. 5.

Villavicencio, Susana (2008), Sarmiento y la nación cívica. Buenos Aires: Eudeba.

Zarka, Yves-Charles (2001), "Vico et la mutation de l'héroïsme. Force et fragilité du héros", Figures du pouvoir. Etudes de philosophie politique de Machiavel à Foucault. PUF p. 40. 